\title{
Thought suppression and traumatic intrusions in undergraduate students: A correlational study
}

Citation for published version (APA):

Rassin, E. G. C., Merckelbach, H. L. G. J., \& Muris, P. E. H. M. (2001). Thought suppression and traumatic intrusions in undergraduate students: A correlational study. Personality and Individual Differences, 31, 485-493. https://doi.org/10.1016/S0191-8869(00)00152-5

Document status and date:

Published: 01/01/2001

DOI:

10.1016/S0191-8869(00)00152-5

Document Version:

Publisher's PDF, also known as Version of record

\section{Please check the document version of this publication:}

- A submitted manuscript is the version of the article upon submission and before peer-review. There can be important differences between the submitted version and the official published version of record.

People interested in the research are advised to contact the author for the final version of the publication, or visit the DOI to the publisher's website.

- The final author version and the galley proof are versions of the publication after peer review.

- The final published version features the final layout of the paper including the volume, issue and page numbers.

Link to publication

\footnotetext{
General rights rights.

- You may freely distribute the URL identifying the publication in the public portal. please follow below link for the End User Agreement:

www.umlib.nl/taverne-license

Take down policy

If you believe that this document breaches copyright please contact us at:

repository@maastrichtuniversity.nl

providing details and we will investigate your claim.
}

Copyright and moral rights for the publications made accessible in the public portal are retained by the authors and/or other copyright owners and it is a condition of accessing publications that users recognise and abide by the legal requirements associated with these

- Users may download and print one copy of any publication from the public portal for the purpose of private study or research.

- You may not further distribute the material or use it for any profit-making activity or commercial gain

If the publication is distributed under the terms of Article $25 \mathrm{fa}$ of the Dutch Copyright Act, indicated by the "Taverne" license above, 


\title{
Thought suppression and traumatic intrusions in undergraduate students: a correlational study
}

\author{
Eric Rassin*, Harald Merckelbach, Peter Muris \\ Department of Psychology, Maastricht University, PO Box 616,6200 MD Maastricht, The Netherlands
}

Received 15 December 1999; received in revised form 12 June 2000; accepted 12 July 2000

\begin{abstract}
Thought suppression (i.e. the process of consciously trying to avoid certain thoughts) is claimed to promote memory loss, but also to increase the frequency of intrusive thoughts (i.e. hyperaccessibility). Although these effects seem contradictory, Wegner, Quillian and Houston [Wegner, D. M., Quillian, F., \& Houston, C. (1996). Memories out of order: Thought suppression and the disassembly of remembered experience. Journal of Personality and Social Psychology, 71, 680-691.] succeeded in reconciling them by postulating the "scene activation" hypothesis. According to this hypothesis, hyperaccessibility of isolated intrusive memories, due to thought suppression, leads to perceived fragmentation (i.e. snapshot likeness) of the memory of the whole event, ultimately resulting in a perception of (partial) memory loss. To investigate this chain of events, undergraduate students $(n=110)$ completed questionnaires about thought suppression and their memories of highly adverse experiences. Correlational analyses revealed that thought suppression was positively related to hyperaccessibility, snapshot likeness, and memory loss. Structural equation modelling elucidated that thought suppression is not necessarily the cause of these memory characteristics. (C) 2001 Elsevier Science Ltd. All rights reserved.
\end{abstract}

Keywords: Structural equation modelling; Thought suppression; Traumatic intrusions; Traumatic memory

\section{Introduction}

In clinical literature, thought suppression refers to conscious attempts to avoid certain thoughts (e.g. Wegner, Schneider, Carter \& White, 1987). Obviously, such attempts play a major role in psychopathological conditions that involve recurrent intrusions (see, for a review, Purdon, 1999). For example, people suffering from Post Traumatic Stress Disorder (PTSD; American Psychiatric Association, 1994) commonly report that they engage in thought suppression whenever

* Corresponding author. Tel.: + 43-3881908; fax: +43-3884196.

E-mail address: e.rassin@psychology.unimaas.nl (E. Rassin). 
trauma memories intrude their consciousness (e.g. Amir, Kaplan, Efroni, Levine, Benjamin \& Kotler, 1997).

There is some dispute as to the precise effects of thought suppression (see, for a review, Rassin, Merckelbach \& Muris, 2000). Some authors argue that thought suppression is a counterproductive defence strategy that produces more rather than fewer thoughts about the to-be-suppressed topic (Wegner et al., 1987). By this view, thought suppression induces a state of "hyperaccessibility" of intrusion-linked material (Wegner \& Erber, 1992). Other researchers claim that thought suppression may be quite successful and may result in rapid decline (or dissociative amnesia) of suppressed information (e.g. Brewin \& Andrews, 1998; Terr, 1993).

Interestingly, a recent laboratory study on suppression and episodic memory by Wegner, Quillian and Houston (1996) found some supporting evidence for the idea that thought suppression may produce both hyperaccessibility and memory undermining effects (but see Rassin, Merckelbach, \& Muris, 1997). In that study, students were exposed to a neutral film clip and were subsequently assigned to one of three conditions: a suppression condition in which students were instructed not to think about the film clip during the remainder of the day, a thinking condition in which students were told to think as much as possible about the film clip, and a no-instruction control condition. Five hours later, students returned to the laboratory and were given a memory test covering several aspects of the film clip. Suppression was found to result in a poor memory of event chronology as well as in an altered perception of one's own memory. More specifically, compared to participants in the other conditions, suppression participants more often described their memory of the film clip as a collection of isolated snapshots rather than a moving film. Wegner et al. argue that this snapshot effect (i.e., the loss of sequence memory) may lead people to experience (a specific form of) memory loss. In their words, "the snapshot effect of suppression suggests that people might indeed do something that resembles the effect attributed to classical repression" (Wegner et al. p. 689). Discussing these findings, they succeed in reconciling the memory undermining snapshot effect with the well-documented paradoxical hyperaccessibility effect of thought suppression. According to their "scene activation" hypothesis, it is not the complete memory of the trauma that intrudes consciousness, but rather specific scenes - probably the most emotional and impressive ones. These specific scenes would then become the targets of suppression attempts. This, in turn, would lead to hyperaccessibility of these scenes, but would also compromise overall (sequence) memory of the event. Thus, the hyperaccessibility effect may lead people to experience intense intrusive memories pertaining to specific scenes, but, at the same time, may result in a perception of declined memory of the event as a whole.

So far, studies in this domain have been preoccupied with the effects of thought suppression on the frequency of unpleasant intrusions. However, it may well be the case that thought suppression also affects the intensity of such intrusions. For example, the hyperaccessibility of traumatic intrusions may, in some cases, result in the development of exaggerated intrusions. Germane to this issue is a study by Merckelbach, Muris, Horselenberg, and Rassin (1998) who found that $22 \%$ of the respondents with traumatic recollections experienced their traumatic intrusions as exaggerations ("worse case scenarios") of the original event. This finding is, of course, difficult to reconcile with the popular notion that intrusive traumatic memories (i.e. flashbacks) are veridical copies of the original trauma (e.g. Van der Kolk \& Fisler, 1995). In discussing these results, Merckelbach et al. speculated that thought suppression may (through its paradoxical hyperaccessibility effect) promote the process of enlargement of traumatic intrusions. 
Interestingly, in clinical literature, traumatic memories have been characterised as both more and less intense than neutral memories. For example, in a study by Ward and Carroll (1997), victims of sexual assault described their traumatic memories as showing enhanced vividness. In contrast, Koss, Figueredo, Bell, Tharan, and Tromp (1996) reported reduced vividness and clarity of traumatic memories in their sample of rape victims. Possibly, this variety in the phenomenal characteristics of traumatic intrusions has to do with the type of post-trauma elaboration that patients engage in, that is, whether or not they rely on thought suppression.

The current study examined the relationship between thought suppression and the characteristics of traumatic intrusions, by analysing questionnaire data. According to Wegner and Zanakos (1994), there are individual differences in the extent to which people rely on thought suppression as a means of dealing with unpleasant thoughts. Some people may engage in thought suppression quite regularly. Therefore, the tendency to cope with unwanted thoughts by suppressing them can be measured. Wegner and Zanakos introduced the White Bear Suppression Inventory (WBSI) as a measure of chronic thought suppression and concluded that suppression, indeed, is a stable defence mechanism. In their words: “... self-reports of thought suppression are reliable over time and thus fulfill an important criterion for recognition as a trait" (Wegner \& Zanakos, p. 624). Undergraduate students completed the WBSI and a questionnaire about their most traumatic experience in the past 2 years. It was hypothesised that thought suppression is related to the intensity of trauma-related intrusions (hyperaccessibility effect) as well as to perceived snapshot likeness of traumatic memory (memory undermining effect).

\section{Method}

\subsection{Participants}

A sample of 110 undergraduate psychology students (81 women) volunteered to participate in the study. Mean age was 19.7 years (S.D. $=1.9$, range: $18-31)$. Students received a small financial compensation for their participation.

\subsection{Measures}

Participants completed two questionnaires. First, the WBSI (Wegner \& Zanakos, 1994; see also Muris, Merckelbach \& Horselenberg, 1996) was completed. The WBSI comprises 15 items that tap the tendency to suppress unwanted thoughts (e.g. "I always try to put problems out of mind"). Items are answered on a 5 -point scale $(1=$ strongly disagree; $5=$ strongly agree). A total score can be calculated by summing across items (range: 15-75), with higher scores indicating a stronger tendency to engage in thought suppression. ${ }^{1}$

\footnotetext{
1 It has been argued that five WBSI items (e.g. "I have thoughts that I cannot stop") pertain to loss of mental control rather than thought suppression per se (Muris et al., 1996). Consequently, a corrected WBSI score can be calculated by summing across the remaining ten items. Analyses in the present study were run with both total WBSI scores and corrected WBSI scores. As these analyses yielded similar results, findings based on the total WBSI scores are pre-
} 
The second questionnaire was developed for the purpose of the present study. This questionnaire contained ten items addressing respondents' memory of a relatively recent traumatic experience. The first item invited respondents to describe briefly the most traumatic event they had experienced over the past 2 years. The reported traumas did not have to satisfy the DSM IV criteria for PTSD (i.e. experiencing, witnessing, or being confronted with an event that involved actual or threatened death or serious injury, or a threat to the physical integrity of oneself or others), but, rather, had to be experienced as traumatic. The next six items pertained to typical hyperaccessibility characteristics of traumatic intrusions in the weeks after the incident and were adapted from the Merckelbach et al. (1998; see also VanOyen Witvliet, 1997) study. These items were answered by means of $100 \mathrm{~mm}$ Visual Analogue Scales (VASs), and addressed the frequency of intrusions $(0=$ never; $100=$ all the time $)$, controllability $(0=$ completely controllable; $100=$ completely uncontrollable), emotionality $(0=$ not at all emotional; $100=$ extremely emotional $)$, accompanying bodily sensations $(0=$ not at all; $100=$ very much $)$, whether or not the respondent had dreamt about the incident $(0=$ never; $100=$ very frequently), and correspondence between the content of the intrusion and the original event $(0=$ the intrusion is a paler version; $100=$ the intrusion is an exaggerated version). In accordance with the Merckelbach et al study, these items were collapsed into an "overall hyperaccessibility" variable $(\alpha=0.83)$. The next three items pertained to respondents' present-day memory of the traumatic incident. Thus, one item asked to what extent the respondent still had traumatic intrusive thoughts $(0=$ never; $100=$ all the time $)$. A second item asked respondents to indicate whether their memory for the incident was fluent or rather a compilation of isolated snapshots $(0=$ fluent; $100=$ snapshots $)$. Lastly, they were asked if there had ever been a period in which they had experienced memory loss with respect to the incident $(0=$ not at all; $100=\mathrm{I}$ experienced such memory loss $)$.

\subsection{Data analysis}

Data were analysed by means of Pearson correlations and structural equation modelling (EQS; Bentler, 1989). EQS produces several goodness-of-fit indices indicating how well the tested model accounts for the observed correlational structure of the data. In the present study, the following indices were used: (1) the Chi square $\left(\chi^{2}\right)$ Goodness-of-Fit value, which is required to be nonsignificant for the tested model to provide a good fit for the data; (2) the Average off diagonal Absolute Standardised Residuals (AASR), which should not exceed 0.05 in order for the model to fit the data well; (3) Akaike's Information Criterion (AIC) which is a fit index that takes into account the parsimony of the tested model (i.e. the number of included paths); AIC is a relative measure, i.e., the model with the smallest number provides the best fit; and (4) the Comparative Fit Index (CFI) which compares the fit of the tested model with that of the hypothetical model in which none of the variables are correlated. A CFI of 0.90 or higher indicates that the tested model fits the data well (see, for an extensive discussion of these indices, Schumacker \& Lomax, 1996).

\section{Results}

The types of trauma reported by respondents are listed in Table 1. As can be seen, the most frequently mentioned traumatic event involved death of a person close to the respondent (see also 
Merckelbach et al. 1998; Wessel \& Merckelbach, 1994). It should be noted that across the different trauma types, $16.5 \%$ of the respondents reported to have been a victim (e.g. assault), $13.8 \%$ reported having been a witness to a discrete traumatic incident (e.g. accident), and 69.7\% reported experiences that were of a more schematic nature and involved a longer time span (e.g. divorce of parents, being stalked, or suffering from a chronic illness). Analysis of variance (ANOVA) revealed that these three groups did not differ with respect to WBSI scores: $F(2$, $106)=2.0, P=0.15$. Additionally, results of a multivariate analysis of variance (MANOVA) revealed that there were no reliable group differences in any of the memory indices: $F(8$, $194)=1.2, P=0.27$. Given this lack of group differences, it was decided to collapse data across the different trauma types.

Mean scores and Pearson product-moment correlations are presented in Table 2. As can be seen, thought suppression correlated modestly with all memory characteristics, such that stronger suppression tendencies were related to hyperaccessibility, recent intrusions, snapshot like recollections, and self-reported memory loss. As well, several memory characteristics correlated with each other. To explore these associations in more detail, structural equation modelling was employed. The tested models were inspired by the obtained correlations and were, furthermore, limited by the following considerations. To begin with, hyperaccessibility had to precede recent

Table 1

Frequency of reported traumatic events $(n=110)$

\begin{tabular}{lc}
\hline Type of event & Frequency \\
\hline Death & $47(42.7 \%)$ \\
Illness & $15(13.6 \%)$ \\
Accident & $12(10.9 \%)$ \\
Interpersonal conflicts & $10(9.1 \%)$ \\
Harassment or assault & $8(7.3 \%)$ \\
Breaking up a relationship & $6(5.5 \%)$ \\
Exposure to a phobic object & $3(2.7 \%)$ \\
Miscellaneous (e.g. bad drug trip) & $9(8.2 \%)$ \\
\hline
\end{tabular}

Table 2

Mean scores (and standard deviations) on the White Bear Suppression Inventory (WBSI) and on the intrusion characteristics variables and correlations $(n=110)^{\mathrm{a}}$

\begin{tabular}{|c|c|c|c|c|c|}
\hline & \multirow[t]{2}{*}{ Mean (S.D.) } & \multicolumn{4}{|l|}{ Correlations } \\
\hline & & WBSI & $\mathrm{H}$ & RIM & SL \\
\hline WBSI & $42.8(9.0)$ & & & & \\
\hline $\mathrm{H}$ & $47.4(17.0)$ & $0.21 *$ & & & \\
\hline RIM & $37.1(22.4)$ & $0.17 *$ & $0.52 * *$ & & \\
\hline SL & $52.1(24.9)$ & $0.24 * *$ & -0.11 & 0.02 & \\
\hline TML & $29.1(25.3)$ & $0.22 *$ & $0.39 * *$ & $0.36^{* *}$ & $0.17^{*}$ \\
\hline
\end{tabular}

${ }^{a}$ H, hyperaccessibility; RIM, recent intrusive memories; SL, snapshot likeness; TML, temporal memory loss.

${ }^{*} P<0.05$;

${ }^{* *} P<0.01$ (one-tailed). 
intrusive memories, snapshot likeness, and temporal memory loss, since the former characteristic pertained to the weeks immediately after the incident, while the latter characteristics pertained to present-day memory. Second, thought suppression might be placed anywhere in the causal chain, because the WBSI does not specify the when and why of suppression attempts. However, we decided that WBSI scores should not be the consequence of snapshot likeness or temporal memory loss, given that such pathways would seem theoretically unlikely: there is little reason to assume that people who presently report snapshot like recollections will therefore tend to suppress such recollections. A second reason to exclude snapshot likeness and temporal memory loss — but also recent intrusive memories - as a cause of thought suppression is that thought suppression as measured by the WBSI is a rather global and stable coping strategy. By this view, it is implausible that recent memory characteristics affect the suppression tendency tapped by the WBSI.

In the first model, the four memory characteristics are exclusively affected by the WBSI. This model had poor fit indices, i.e. its $\chi^{2}$-value was significant $(P<0.001)$, there was too much unexplained variance $(>0.05)$, and the CFI was low $(<0.24)$. Next, a model was tested in which thought suppression produces hyperaccessibility, while hyperaccessibility promotes recent intrusions, snapshot likeness, and temporal memory loss. After modifications based on results of the Lagrange Multiplier test for adding parameters and the Wald test for dropping parameters, Model 2 (shown in Fig. 1) proved to provide a good fit. Basically, this model holds that thought suppression directly influences hyperaccessibility, snapshot likeness, and temporal memory loss. However, reversal of the causal link between thought suppression and hyperaccessibility (i.e. hyperaccessibility preceding thought suppression) resulted in a third model, which produced fit indices similar to those of Model 2. Therefore, a fourth model was tested, in which thought suppression and hyperaccessibility act as relatively independent entities that are allowed to covary. This model provided the best fit indices. Fit indices for the four models are summarised in Table 3.

\section{Discussion}

The results of the present study can be summarised as follows. When asked to describe the most traumatic experience over the past 2 years, $16 \%$ of the respondents reported having been the victim in an acute traumatic event, 14\% reported having witnessed a discrete traumatic event, and $70 \%$ reported traumatic experiences that involved a process rather than a single, discrete incident. As an aside, it is noteworthy that a substantial percentage of the participants in the present study indicated that in the weeks after the traumatic event, their intrusive memories had taken the form of a worse case scenario. That is, $17.4 \%$ of the participants had a score that exceeded 60 on the pertinent VAS. This finding replicates previous results (Merckelbach et al., 1998) and casts further doubts on the claim that traumatic intrusions possess photographic accuracy (e.g. Van der Kolk \& Fisler, 1995). Instead, our results and those of others (Schwartz, Kowalski \& McNally, 1993; Southwick, Morgan, Nicolaou \& Charney, 1997) suggest that the content of traumatic intrusions can be influenced by post-trauma elaboration and reconstruction (e.g. Safer, Christianson, Autry, \& Österlund, 1998). A case in point is a study by Bryant and Harvey (1998). These authors noted that survivors of motor vehicle accidents who suffer from organic amnesia may later develop traumatic intrusions about these accidents. Often these 
Development of Traumatic Memory Characteristics.

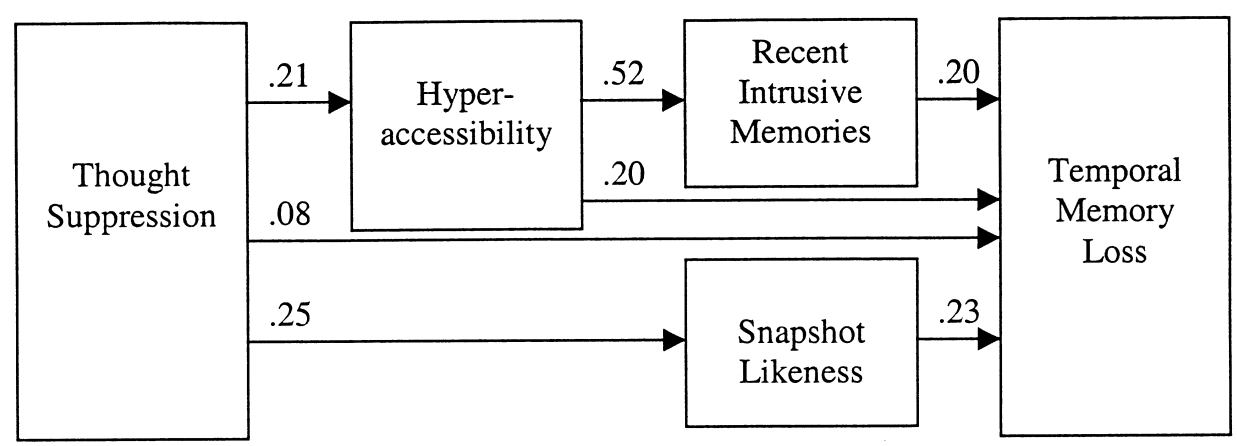

\section{Model 2.}

Note. Model 3 consists of a reversal of the link between thought suppression and hyperaccessibility.

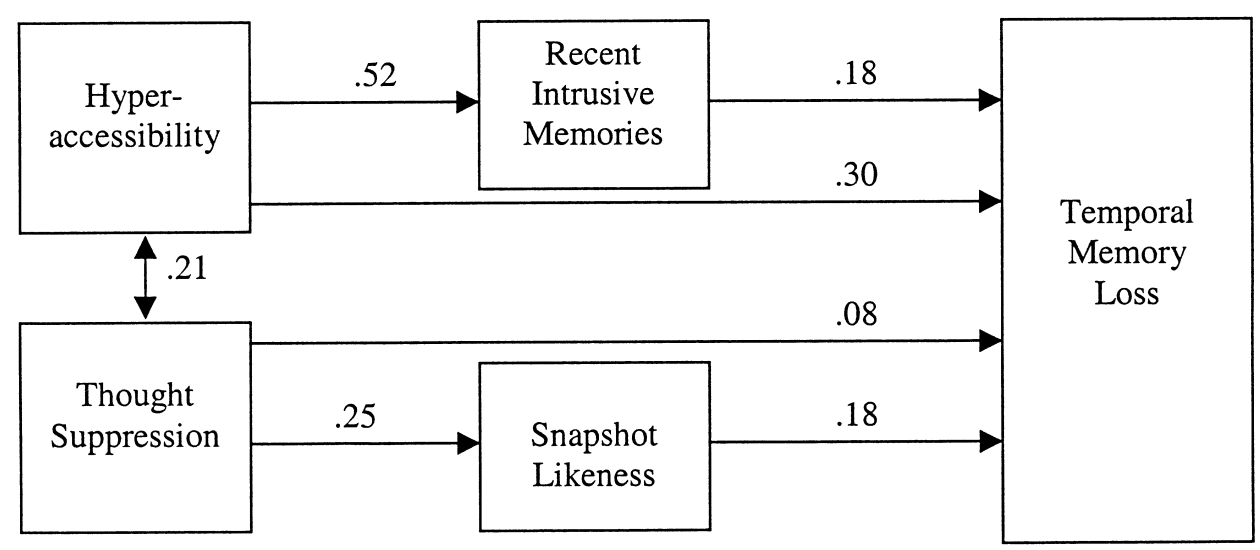

\section{Model 4.}

Fig. 1. Plausible pathways describing the role of thought suppression in the development of traumatic memory characteristics.

intrusions do not correspond with third party accounts of the accident. As another example, Lipinski and Pope (1994) found that patients suffering from obsessive-compulsive disorder may produce such vivid imagery that their therapists mistake these imaginations for flashbacks of childhood traumas. These findings underline the notion that traumatic intrusions do not necessarily represent accurate recollections. 
As to the role of thought suppression, the current study found a number of significant, but modest associations between chronic thought suppression (as indexed by the WBSI) and phenomenal characteristics of traumatic intrusions. More specifically, thought suppression was correlated with hyperaccessibility characteristics (e.g. frequency, uncontrollability, intensity, and worse case scenario) of intrusions in the weeks following the incident. As well, thought suppression was positively associated with frequency of recent traumatic intrusions, perceived snapshot likeness of present-day memory of the incident, and self-reported memory loss. This pattern of results is in line with the alleged effects of thought suppression (e.g. Wegner et al., 1996). That is, hyperaccessibility in the weeks after the incident accords well with the often reported increased frequency of intrusions, while snapshot likeness and perceived memory loss suggest memory undermining effects. However, results of the structural equation modelling analyses revealed that a simple causal model in which thought suppression serves as the only antecedent of all these phenomena is unlikely. Rather, our results favour a model in which thought suppression promotes perceived snapshot likeness and, to a lesser extent, self-reported memory loss, but is not necessarily an antecedent of hyperaccessibility and recent intrusive memories. Thus, while it is tempting to interpret the significant correlation between thought suppression and hyperaccessibility $(r=0.21)$ in terms of chronic suppression fostering intense intrusions, structural equation modelling shows that the opposite causal direction cannot be ruled out. Future studies should examine whether adverse life experiences may shape chronic coping strategies such as thought suppression.

In sum, then, we found evidence to suggest that thought suppression promotes perceived snapshot likeness. However, in spite of the presence of moderate correlations, little or no support was found for the idea that thought suppression is the main vehicle behind hyperaccessibility. These findings cast doubts on Wegner et al.'s (1996) hypothesis that hyperaccessibility of specific scenes is the cause of perceived snapshot likeness. By their view, suppression may paradoxically result in more intrusions, which in turn leads to a perceived snapshot likeness of one's memory. Yet, the current results suggest that hyperaccessibility of intrusions does not function as a conditio sine qua non in the causal chain between thought suppression and perceived snapshot likeness.

A number of limitations of the present study need to be acknowledged. For one thing, the present study was based on cross-sectional self-reports. Furthermore, we used a broad definition of trauma and relied on a non-clinical sample. Future research is needed to further investigate the precise mechanism by which thought suppression promotes perceived snapshot likeness of traumatic memories.

Table 3

Fit indices for the four models ${ }^{\mathrm{a}}$

\begin{tabular}{lrccrr}
\hline & \multicolumn{1}{c}{$\chi^{?}$} & $P$ & AASR & AIC & CFI \\
\hline Model 1 & 56.54 & $<0.001$ & 0.14 & 44.54 & 0.24 \\
Model 2 & 5.84 & 0.12 & 0.04 & 0.15 & 0.96 \\
Model 3 & 5.84 & 0.12 & 0.04 & 0.15 & 0.96 \\
Model 4 & 4.55 & 0.21 & 0.03 & 1.50 & 0.98 \\
\hline
\end{tabular}

a AASR, Average off-diagonal Absolute Standardised Residuals; AIC, Akaike's Information Criterion; CFI, Comparative Fit Index. 


\section{References}

American Psychiatric Association (1994). Diagnostic and statistical manual for mental disorders, fourth edition (DSM $I V)$. Washington: APA.

Amir, M., Kaplan, Z., Efroni, R., Levine, Y., Benjamin, J., \& Kotler, M. (1997). Coping styles in post-traumatic stress disorder (PTSD) patients. Personality and Individual Differences, 23, 399-405.

Bentler, P. (1989). EQS structural relations program manual. Los Angeles, CA: BMDP Statistical Software.

Brewin, C. R., \& Andrews, B. (1998). Recovered memories of trauma: phenomenology and cognitive mechanisms. Clinical Psychology Review, 18, 949-970.

Bryant, R. A., \& Harvey, A. G. (1998). Traumatic memories and pseudomemories in posttraumatic stress disorder. Applied Cognitive Psychology, 12, 81-88.

Koss, M. P., Figueredo, A. J., Bell, I., Tharan, M., \& Tromp, S. (1996). Traumatic memory characteristics: a crossvalidated mediational model of response to rape among employed women. Journal of Abnormal Psychology, 105, 421-432.

Lipinski, J. F., \& Pope, H. G. (1994). Do "flashbacks" represent obsessional imagery? Comprehensive Psychiatry, 35, 245-247.

Merckelbach, H., Muris, P., Horselenberg, R., \& Rassin, E. (1998). Traumatic intrusions as 'worse case scenario's'. Behaviour Research and Therapy, 36, 1075-1079.

Muris, P., Merckelbach, H., \& Horselenberg, R. (1996). Individual differences in thought suppression. The white bear suppression inventory: factor structure, reliability, validity and correlates. Behaviour Research and Therapy, 34, 501513.

Purdon, C. (1999). Thought suppression and psychopathology. Behaviour Research and Therapy, 37, 1029-1054.

Rassin, E., Merckelbach, H., \& Muris, P. (1997). Effects of thought suppression on episodic memory. Behaviour Research and Therapy, 35, 1035-1038.

Rassin, E., Merckelbach, H., \& Muris, P. (2001). Paradoxical and less paradoxical effects of thought suppression: a critical review. Clinical Psychology Review (in press).

Safer, M. A., Christianson, S., Autry, M. W., \& Österlund, K. (1998). Tunnel memory for traumatic events. Applied Cognitive Psychology, 12, 99-117.

Schumacker, R. E., \& Lomax, R. G. (1996). A beginner's guide to structural equation modelling. Mahwah, NJ: Lawrence Erlbaum.

Schwartz, E. D., Kowalski, J. M., \& McNally, R. J. (1993). Malignant memories: Post-traumatic changes in memory in adults after a school shooting. Journal of Traumatic Stress, 6, 545-553.

Southwick, S. M., Morgan, C. A., Nicolaou, A. L., \& Charney, D. S. (1997). Consistency of memory for combatrelated traumatic events in veterans of Operation Desert Storm. American Journal of Psychiatry, 154, 173-177.

Terr, L. (1993). Unchained memories: true stories of traumatic memories lost and found. New York: Basic books.

Van der Kolk, A., \& Fisler, R. (1995). Dissociation and the fragmentary nature of traumatic memories: Overview and exploratory study. Journal of Traumatic Stress, 8, 505-525.

Van Oyen Witvliet, C. (1997). Traumatic intrusive imagery as an emotional memory phenomenon: A review of research and explanatory information processing theories. Clinical Psychology Review, 17, 509-536.

Ward, G., \& Carroll, M. (1997). Reality monitoring for sexual abuse memories. Applied Cognitive Psychology, 11, 293304.

Wegner, D. M., \& Erber, R. (1992). The hyperaccessibility of suppressed thoughts. Journal of Personality and Social Psychology, 63, 903-912.

Wegner, D. M., \& Zanakos, S. (1994). Chronic thought suppression. Journal of Personality, 62, 615-640.

Wegner, D. M., Quillian, F., \& Houston, C. (1996). Memories out of order: Thought suppression and the disassembly of remembered experience. Journal of Personality and Social Psychology, 71, 680-691.

Wegner, D. M., Schneider, D. J., Carter, S. R., \& White, T. L. (1987). Paradoxical effects of thoughts suppression. Journal of Personality and Social Psychology, 53, 5-13.

Wessel, I., \& Merckelbach, H. (1994). Characteristics of traumatic memories in normal subjects. Behavioural and Cognitive Psychotherapy, 22, 315-324. 